\title{
Chapter 8 \\ What Does the TIMSS Tell Us About Teacher Effectiveness?
}

\begin{abstract}
The central aim of this report was to investigate what international comparative assessments could reveal about the role of teachers in influencing student outcomes. A series of analyses attempted to identify potential trends in teacher quality and instructional metrics over time and their relationship with student achievement, but found no strong evidence for consistent predictable relationships between commonly-employed indicators of teacher effectiveness and student outcomes (both within and across educational systems). Further, although inequality in student outcomes remains pervasive across education systems, teacher quality is less subject to inequality, and, indeed, many countries have seen a rise in formal preparation to teach mathematics over the twenty years of IEA's Trends in International Mathematics and Science Study (TIMSS). While improving conventional measures of teacher quality may not have a significant impact on educational inequality, there is some evidence that increasing the average amount of time spent on teaching mathematics may reduce inequalities in student achievement. Researchers and policymakers should be extremely cautious about applying the associations identified in one education systems to a very different educational context. The results indicate that teachers with similar experience, credentials, and instructional strategies may regardless produce quite different results, indicating that parents, policymakers, community institutions, and cultural context likely play a powerful role in determining student outcomes.
\end{abstract}

Keywords Educational equity $\cdot$ Student achievement $\cdot$ Teacher quality $\cdot$ Trends in International Mathematics and Science Study (TIMSS)

The research questions posed in the first chapter of this work were as follows:

(1) Are there identifiable trends in teacher quality and instructional metrics over time?

(2) What are the relationships between student achievement and different types of teacher quality and instructional metrics?

(3) How stable are these relationships across time and by statistical method?

(4) What are the relationships between student equity and different types of teacher quality and instructional metrics? 
Chapter 4 focused on the first research question. Country-level descriptive data at grade four revealed that some teacher characteristics (e.g., teacher education) were fairly stable across time, but there was wide temporal variation in teacher behaviors like instructional alignment with national curricula and time spent on teaching mathematics. However, there were important differences in these variables between grades four and eight; at grade eight there was far greater variation in levels of teacher education, but less variation in time spent on teaching mathematics. Meanwhile, many countries saw increases in teacher characteristics like formal preparation to teach mathematics, perhaps in response to policy initiatives prompted by the TIMSS results. At both grades, there were many countries that demonstrated an increase in teacher self-efficacy over the twenty years of TIMSS. At both grades, some countries exhibited consistency in levels of teacher experience, while others demonstrated wide variation in this variable between cycles of TIMSS.

Research question 2 was addressed in Chaps. 5 and 6. Chapter 5 identified relationships between teacher quality measures and mean student outcomes using several statistical approaches (pooled within country, students clustered within classrooms, classroom-level means, and country-level fixed effects models). Chapter 6 used multilevel structural equation modeling to explore the interactive effect of teacher characteristics and behaviors. The key takeaways from all of these analyses were:

(1) There were no generally valid relationships between teacher characteristics and student mean outcomes, rather there were dramatically different relationships from one educational system to the next;

(2) Of the two teacher behaviors associated with opportunity to learn considered in this study, time spent on teaching mathematics was the only behavior identified as statistically significant across countries in the fixed-effects model; and

(3) Teacher instructional alignment with national curricular expectations has exceptionally weak associations with student outcomes.

Chapter 5 also considered research question 3, examining the within-country consistency of statistical estimates across time and by analytical method. These analyses indicated that there were often differences in the strength and direction of many associations between teacher variables and student mathematics performance. This instability should give pause to researchers and policymakers who may be too quick to draw conclusions from one cycle of data or derived using one statistical method. The sensitivity of standard error estimates, which are critical to determining whether a relationship is statistically significant, should likewise warn researchers against neglecting the complex sampling design of TIMSS.

The topic of student equity, addressed in research question 4, was the subject of Chap. 7. Consistent with other research (e.g., Schmidt et al. 2015), our analysis demonstrated that there was considerable educational inequality, whether equity is understood simply as variation or as differences between high- and low-SES classrooms, and that this inequality varies considerably between education systems. However, there is was only a very weak relationship between this inequality and conventional measures of teacher effectiveness, whether those metrics were related to 
teacher preparation or to teacher behaviors. In short, at least according to our analyses, improving conventional measures of teacher quality may not have a significant impact on educational inequality. However, there is some evidence that increasing the average amount of time spent on teaching mathematics may reduce inequalities in student achievement.

The research we have presented here is certainly extensive, but by no means conclusive. TIMSS operationalizes teacher-level variables in very specific ways, distinct from those in other research that have suggested stronger associations for teacher effectiveness measures. Teacher-reported preparation to teach mathematics topics is a less precise measure of teacher content knowledge than tests of that knowledge, which some studies have found to be related to student outcomes. Similarly, instructional alignment is based on very different assumptions from curricular intensity. Beyond this, there are other methods for exploring the potential of teacher instruction; for example, alignment and teacher preparedness is defined with a summary index, rather than being matched to more specific dimensions of student learning.

It should be acknowledged that the design of TIMSS carries with it certain limitations. Because TIMSS only selects one or two classrooms within a given school, it makes it extremely difficult to differentiate teacher from school effects, or to identify within-school, between-classroom heterogeneity. The cross-sectional nature of TIMSS, and the lack of consistent country participation across cycles, also presents challenges.

If there is one lesson that should be absorbed by readers of this report, it would be that researchers and policymakers should be extremely cautious about applying the associations identified in one education systems to a very different educational context. Simple transference of policy ideas that have enjoyed apparent success in one educational system can yield unexpected (or even disastrous) consequences in another. International comparative research is thus an extremely fruitful way to test the universality of given approaches. Further, this study suggests that the search for broadly applicable, reliable, easily collected measures of teacher effectiveness is likely to be long and difficult.

On a more positive note, we found that replicating statistical models across different cultural contexts and time periods can be extremely fruitful. There is a strong temptation for researchers situated within a given educational system, or using a given set of data, to draw overly broad generalizations about the universality of their findings. Large-scale analyses employing studies from different countries, and replicated across time, can serve as a useful check on the robustness of scholarly work.

Finally, our findings pose a challenge to those who would place too much responsibility for perceived educational ills on teachers. At least in the United States, there has been a tendency among some policy activists to present "bad teachers" as the reason for poor educational outcomes. The results of this study suggest that teachers with similar experience, credentials, and instructional strategies produce quite different results, which could mean that adequate cross-national measures of high-quality teaching are lacking, or that teachers' effectiveness is conditioned on other circumstances. The totality of the educational system itself, and the social 
structures it rests upon, powerfully shape student outcomes. Accordingly it is a profound mistake to place too high a burden on teachers (or schools). Teachers are essential to the educational project, but parents, policymakers, community institutions, and cultural context may also play a powerful role in student outcomes.

\section{Reference}

Schmidt, W., Burroughs, N., Zoido, P., \& Houang, R. (2015). The role of schooling in perpetuating educational inequality: An international perspective. Education Researcher, 44(4), 371-386.

Open Access This chapter is licensed under the terms of the Creative Commons AttributionNonCommercial 4.0 International License (http://creativecommons.org/licenses/by-nc/4.0/), which permits any noncommercial use, sharing, adaptation, distribution and reproduction in any medium or format, as long as you give appropriate credit to the original author(s) and the source, provide a link to the Creative Commons license and indicate if changes were made.

The images or other third party material in this chapter are included in the chapter's Creative Commons license, unless indicated otherwise in a credit line to the material. If material is not included in the chapter's Creative Commons license and your intended use is not permitted by statutory regulation or exceeds the permitted use, you will need to obtain permission directly from the copyright holder. 